\title{
ANALISA KEPUTUSAN PEMBELIAN SECARA ONLINE PADA MARKETPLACE BATIK PEKALONGAN
}

\author{
Heny Herawati, Ristanto \\ Prodi Manajemen, Fakultas Ekonomi Universitas Islam As-Syafi'iyah \\ Henyherawati.feb@uia.ac.id
}

\begin{abstract}
ABSTRAK
Pertumbuhan usaha Mikro, Kecil dan Menengah di Pekalongan saat ini masih perlu untuk ditingkatkan, Oleh karena itu perlu suatu cara atau metode tertentu untuk memperbaikinya bagaimana mereka dapat menjual produknya dengan baik. Upaya yang harus dilakukan saat ini diantaranya adalah dengan menggunakan melalui media digital dengan penerapannya secara online. Penelitian ini dilakukan bertujuan untuk menganalisa keputusan pembelian secara online pada marketplace Batik pekalongan. Dengan sampel berjumlah 96 responden. Data diperoleh dengan pembagian kuesioner kepada pengrajin dan konsumen batik pekalongan. Hasil analisis menunjukan bahwa 1). Produk mempengaruhi keputusan pembelian secara online pada marketplace batik pekalongan dengan kualitas dan corak atau motif batik yang beraneka ragam. 2). Variabel terendah dalam penelitian ini adalah harga dengan keterjangkauan di masyarakat yang akan mempengaruhi konsumen untuk melakukan keputusan pembelian secara online pada marketplace batik pekalongan
\end{abstract}

Kata kunci : Produk, Harga, Keputusan pembelian.

\begin{abstract}
The growth of Micro, Small and Medium Enterprises in Pekalongan currently still needs to be improved. Therefore, a certain method or method is needed to improve how they can sell their products well. Efforts that must be made at this time include using digital media with its application online. This research was conducted with the aim of analyzing online purchasing decisions at the Pekalongan Batik marketplace With a sample of 96 respondents. The data was obtained by distributing questionnaires to the batik craftsmen and consumers of Pekalongan. The results of the analysis show that 1). Products influence online purchasing decisions on the Pekalongan batik marketplace with various qualities and patterns or batik motifs. 2). The lowest variable in this study is the price with affordability in the community which will influence consumers to make online purchasing decisions at the Pekalongan batik marketplace.
\end{abstract}

Keywords: product, price and purchasing decisions 


\section{PENDAHULUAN}

Teknologi dan informasi di era digitalisasi saat ini berjalan begitu cepat, sehingga menimbulkan persaingan bisnis yang semakin ketat. Perkembangan teknologi mendorong sebuah marketplace untuk go online (Apriyanto. 2016). Sebuah Marketplace yang merupakan transaksi dalam dunia maya dimana pembeli dan penjual melakukan kegiatannya secara elektronik (Taryadi et al., 2015) (Wahana, 2018). Marketplace dirancang untuk mengumpulkan penjual dalam satu tempat di internet, sehingga pembeli dapat mencari dan membandingkan suatu produk dari beberapa penjual yang ada (Ningsih, 2016).(Wahana, 2018).

System marketplace membuat para pengusaha harus memiliki inovatif yang menarik dan kreatifitas yang tinggi dalam melihat perkembangan bisnis yang ada. Yang harus dilakukan saat ini agar berhasil dalam persaingan bisnisnya yaitu dengan membuat strategi kegiatan perusahaannya melalui inovasi dan kreatifitas pada produk barang dan jasanya yang berbeda dengan yang lainnya agar sesuai dengan kebutuhan dan keinginan konsumen.

Perkembangan pengguna internet dapat berpotensi besar terjadinya online shopping. Oleh sebab peluang semakin terbuka lebar bagi pelaku bisnis untuk menjalankan bisnis online di Indonesia. Pengguna internet adalah mereka individu yang terhubung internetnya dengan baik dari perangkat komputer atau perangkat mobile atau perangkat lainnya, baik milik sendiri maupun milik orang lain, atau dari dalam rumah maupun dari luar rumah .

Berdasarkan data We Are Social tahun 2019 sebanyak 4,388 milyar pengguna internet di seluruh dunia, yang terdaftar sebanyak 5,112 milyar, yang aktif berkisar 3,484 milyar dari total penduduk dunia sebanyak 7,676 milyar. Indonesia merupakan negara yang mengalami perkembangan yang cepat dengan $73,3 \%$ aktif di media sosial meningkat dari 64,8\% pada tahun 2018. Untuk jumlah pengguna internet pada tahun 2019 berjumlah 266,9 juta dan aktif di media social 196,7 juta, meningkat jumlah pengguna dari 171 juta ditahun 2019 dengan penetrasi 73.7 persen atau naik sekitar 8,9 persen atau sekitar 25,5 juta pengguna. Dengan perkembangan media social sangat potensial bagi perkembangan UMKM baik yang baru memulai atau yang telah menggunakannya secara online (Susanto et al, 2020) 
Kota Pekalongan sebagai "Kota Batik", merupakan kota penghasil batik terbaik di Jawa Tengah. Pemerintah memberikan dukungan sepenuhnya dalam pemasaran produk batik dengan membangun kampung batik dan pusat-pusat pemasaran untuk memudahkan pembeli untuk berbelanja batik baik dari dalam kota pekalongan maupun dari luar pekalongan. Industri batik di kota Pekalongan yang kini berjumlah 459 unit usaha ( bbpkb.memperindag.go,id, 2020) memberikan kontribusi pada kemajuan perekonomian di Pekalongan, walaupun saat ini Unit Usaha batik yang ada belum secara maksimal tumbuh di pekalongan .Beberapa hal yang membatasi perkembangan industri batik pekalongan diantaranya adanya persaingan klaster, domestik dan persaingan luar negeri, kebijakan harga, permodalan, penyelundupan batik, kebijakan ekonomi, masih minimnya penguasaan teknologi, dan komunikasi dalam pengembangan usahanya. Dengan demikian dapat disimpulkan bahwa permasalahan UMKM batik pekalongan adalah kesulitan dalam melakukan pemasaran untuk produknya .(Prastuti, 2014), (Taryadi et al., 2015)

Produk batik tidak dibeli oleh masyarakat bukan karena tidak menarik, tapi karena produk tersebut belum menemukan konsumen yang tepat dan yang membutuhkan, untuk itu diperlukan wadah khusus untuk melakukan jual beli batik. Selama ini para UKM Pedagang batik melakukan penjualannya secara online di Telegram, Whatsap, facebook. Masalah di lapangan para pedagang batik sangat membutuhkan produk dan harga yang berkualitas agar bisa menarik banyak konsumen, dan sebuah wadah/website aplikasi khusus jual-beli batik yang akan memudahkan UKM pedagang batik untuk berjualan macam-macam jenis batiknya (Firmansyah, 2019).

Marketplace Batik pekalongan adalah sebuah website dan Aplikasi Android yang terdapat didalamnya penjual dan pembeli batik. Produk batik yang ditawarkan kepada masyarakat seperti Baju Batik, Sarung Batik, bahan batik, Celana Batik, dan Accesories batik. Konsumen hanya perlu mengunggah katalog produk untuk mendapatkan produk yang mereka inginkan. Untuk menjadi merchant penjual di marketplace, konsumen dapat langsung mendowloud dan tidak dikenakan tarif atau biaya / Gratis (www.duetoko.com, 2019).

Laporan penjualan Marketplace batik pekalongan pada tahun 2018-2019 produk yang banyak dibeli secara online adalah produk Blues Batik baru mencapai 255 pieces untuk blues perempuan. Hem laki-laki 150 potong, Tunik Perempuan 90 pieces, Kemeja 
Laki-Laki 80 pieces, Seragam Batik 65 pieces, Gamis 46 pieces, Kebaya perempuan 23 pieces, Couple Batik L/P 15 pieces . Dan Give away 12 pieces dibagikan Gratis kepada pelanggan setia batik setiap bulannya di tanggal 1. Sebagian besar konsumen Duetoko Batik terdiri dari pelajar SMA, mahasiswa, dosen, karyawan swasta yang mempunyai rentang usia 17-50 Tahun. Dari data penjualan batik duetoko selama 2 tahun ( 2018-2019 ) menunjukkan bahwa produk Fashion batik Pekalongan belum banyak diminati oleh kalangan masyarakat di Indonesia yang saat ini berjumlah 268.583.016 jiwa ( Jakarta, Kompas.com ). Pengguna produk Batik Pekalongan dengan menggunakan Marketplace Duetoko Batik online baru mencapai 2,74 \% atau sebanyak 736 pieces, hal ini disebabkan batik pekalongan belum mampu bersaing dengan batik lainnya diseluruh tanah air dan karena factor kualitas produk dan harga yang mempengaruhi keputusan konsumen untuk membeli batik pekalongan. Dengan demikian perlunya penelitian untuk mengetahui apa yang menjadi penyebab kurangnya minat beli konsumen batik pekalongan dengan aplikasi Marketplace duetoko dilihat dari segi produk dan harga.

E-Commerce atau penjualan secara internet merupakan suatu proses menjual dan membeli produk secara elektronik menggunakan internet, website, maupun aplikasi baik lainnya yang dilakukan oleh individu maupun organisasi sebagai transaksi bisnis (Laudon, 2014).(Rahman et al., 2017). Marketplace merupakan komunitas bisnis secara elektronik dimana individu maupun badan usaha andil dalam Bisnis e-commerce ( Brunn, Jensen, \& Skovgaard, 2002 ). Keputusan pembelian merupakan proses dimana konsumen melakukan pengambilan keputusan pembelian dan mereka / konsumen benar-benar melakukan pembelian. integrasi yang digunakan adalah bagaimana mengkombinasikan pengetahuan tentang produk / jasa sebagai alternatif perilaku dalam memilih produk /jasa (Peter dan Olson, 2013). Produk merupakan sesuatu yang ditawarkan ke pasar untuk mendapatkan perhatian, dibeli, dikonsumsi atau dipergunakan dan dapat memuaskan kebutuhan dan keinginan konsumen . (Abdullah, 2018). Harga (price) merupakan sejumlah nilai uang yang dapat digunakan sebagai alat tukar untuk mendapatkan pemanfaatan dari kepemilikan atau penggunaan dari barang maupun jasa . (Indrasari, 2019).

Beberapa penelitian terdahulu mengenai keputusan pembelian dipengaruhi oleh factor produk, harga (Fandy, 2015) (Devi, 2019), perdagangan batik dengan marketplace di pekalongan (Taryadi et al., 2015)(Ningsih, 2016), implementasi untuk produk 
marketplace (Rahman et al., 2017)(Wahana, 2018) (Susanto et al., 2020) rancang bangun marketplace produk kewirausahaan (Ningsih, 2016)(Rahman et al., 2017)(Artaya \& Purworusmiardi, 2019)

Berdasarkan teori dan penelitian terdahulu tersebut maka peneliti berencana meneliti permasalahan pada variable produk dan harga batik pekalongan terhadap keputusan pembelian secara online pada marketplace batik pekalongan, Adapun yang menjadi permasalahan pada penelitian ini adalah 1. Apakah produk berpengaruh terhadap keputusan pembelian secara online pada Marketplace batik pekalongan 2. Apakah harga berpengaruh terhadap keputusan pembelian secara online pada Marketplace batik pekalongan.

Yang menjadi tujuan dari penelitian ini adalah untuk mengetahui apakah produk, harga berpengaruh terhadap keputusan pembelian secara online pada Marketplace batik pekalongan.

\section{METODE PENELITIAN}

Penelitian yang dilakukan merupakan penelitian survey dilapangan dengan menggunakan metode kuantitatif (Sugiono, 2017). Untuk mendapatkan data penelitian maka penulis melakukan wawancara dan questioner kepada UMKM Batik dan konsumen pengguna Batik di Kota Pekalongan . Bahan questioner dan wawancara yang digunakan dalam penelitian berdasarkan pada indikator dari masing-masing variable sesuai definisi operasional yang ada, seperti dibawah ini :

\section{Tabel 1. Definisi Operasional}

\begin{tabular}{|c|c|c|c|}
\hline Variabel & Definisi & Indikator & Skala \\
\hline $\begin{array}{l}\text { Produk } \\
(\mathrm{X} 1)\end{array}$ & $\begin{array}{l}\text { Sesuatu yang di tawar kan } \\
\text { untuk dimiliki, dan } \\
\text { digunakan, serta dapat } \\
\text { memenuhi kebutuhan dan } \\
\text { Keinginan konsumen. }\end{array}$ & $\begin{array}{l}\text {-Variasi } \\
\text {-Kualitas } \\
\text {-Desain } \\
\text {-Merek }\end{array}$ & Likert \\
\hline $\begin{array}{l}\text { Harga } \\
(\mathrm{X} 2)\end{array}$ & $\begin{array}{l}\text { nilai dari produk batik } \\
\text { pekalongan yang diukur } \\
\text { dengan jumlah uang. }\end{array}$ & $\begin{array}{l}\text {-harga terjangkau } \\
\text {-Kesesuaian harga } \\
\text { - manfaat produk } \\
\text {-Daya saing harga }\end{array}$ & Likert \\
\hline $\begin{array}{l}\text { Keputusan } \\
\text { Pembelian }\end{array}$ & $\begin{array}{l}\text { Proses pengambilan } \\
\text { keputusan secara online } \\
\text { yang melibatkan individu }\end{array}$ & $\begin{array}{l}\text { Kemantapan produk } \\
\text {-Kebiasaan membeli } \\
\text { produk }\end{array}$ & \\
\hline
\end{tabular}




\begin{tabular}{l|l|l|l|}
$\begin{array}{l}\text { Secara } \\
\text { Online } \\
(Y)\end{array}$ & $\begin{array}{l}\text { dalam mendapatkan, } \\
\text { menggunakan, menilai,s } \\
\text { atau mengabaikan produk } \\
\text { batik pekalongan }\end{array}$ & $\begin{array}{l}\text {-Pembelian ulang } \\
\text {-Memberikan } \\
\text { ekomendasi kepada } \\
\text { orang lain }\end{array}$ & Likert \\
\hline
\end{tabular}

Populasi penelitian ini adalah pengguna marketplace batik pekalongan dan pembeli batik di Pekalongan yang berbelanja batik. Maka rumus yang digunakan adalah rumus Lemeshow

$$
n=\frac{(1.96) 2 \times 0.5 \times 0.5}{(0.1) 2}=96.04
$$

Jumlah sample yang digunakan oleh peneliti dibulatkan menjadi 96 responden. Metode yang digunakan dengan menggunakan skala likerts. Metode analisis yang digunakan adalah statistic deskriptif, dengan analisis regresi, korelasi dan koefisien determinasi.

Kerangka pemikiran berdasarkan teori dan tinjauan penelitian terdahulu, dengan variabel independent adalah produk dan harga, dan variabel dependennya adalah keputusan pembelian secara online. Maka hubungan antara variable tersebut dapat digambarkan dalam kerangka pemikiran sebagai berikut:

\section{Gambar 1. Kerangka Pemikiran}

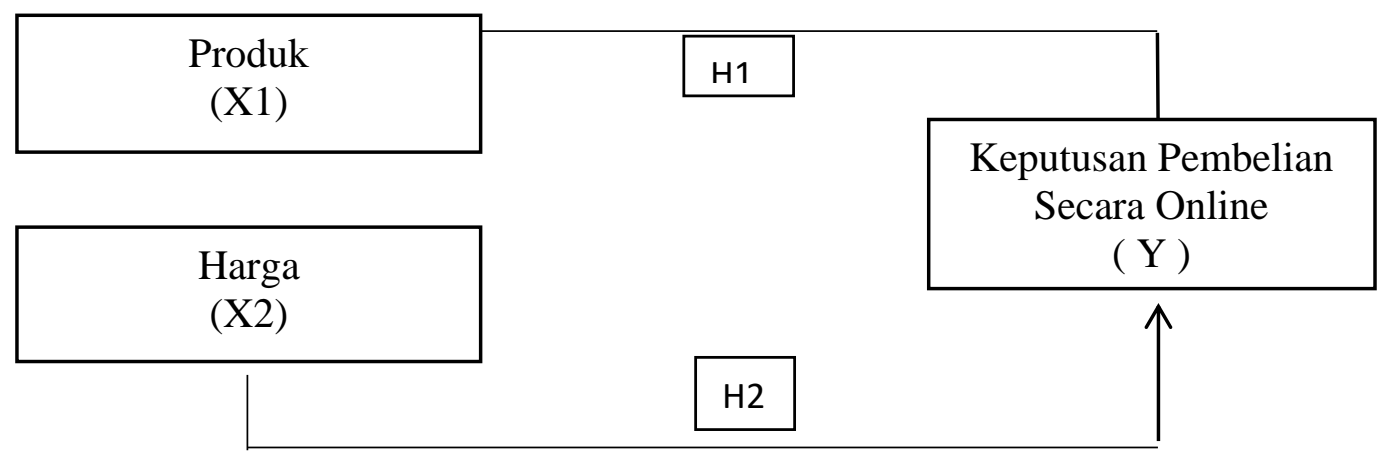

\section{HASIL PENELITIAN}

Untuk mengetahui pertanyaan atau pernyataan dapat dikatakan valid atau tidak maka diperlukan uji validitas,yaitu dengan cara melihat distribusi nilai $r_{\text {tabel }}$ lalu membandingkan dengan nilai $r_{\text {hitung. Apabila }} r_{\text {hitung }}>r_{\text {tabel }}$ adalah valid, apabila $r_{\text {hitung }}<$ $r_{\text {tabel }}$ adalah tidak valid. Nilai $r_{\text {tabel }}$ didapatkan dari nilai $d f-2$, nilai $d f$, sampel yang 
digunakan sebanyak 20 responden, sehingga nilai untuk melihat pada tabel adalah r 20$2=18$ dengan signifikan 5\% maka didapatkan nilai $r_{\text {tabel }}$ sebesar 0,444 dan hasil dari uji validitas $r_{\text {hitung }}>r_{\text {tabel }}$ sebesar 0,444 maka pernyataan produk, harga dan keputusan pembelian dinyatakan valid

Tabel 2. Hasil Uji Validitas

\begin{tabular}{cccccc}
\hline No & $\begin{array}{c}\mathbf{r}_{\text {hitung }} \\
\mathbf{X 1}\end{array}$ & $\mathbf{r}_{\text {hitungX2 }}$ & $\mathbf{r}_{\text {hitung } \mathbf{Y}}$ & $\mathbf{r}_{\text {tabel }}$ & Keterangan \\
\hline 1 & 0,650 & 0,560 & 0,915 & 0,444 & Valid \\
2 & 0,601 & 0,632 & 0,917 & 0,444 & Valid \\
3 & 0,467 & 0,801 & 0,918 & 0,444 & Valid \\
4 & 0,858 & 0,716 & 0,758 & 0,444 & Valid \\
5 & 0,761 & 0,897 & 0,803 & 0,444 & Valid \\
6 & 0,640 & 0,793 & 0,914 & 0,444 & Valid \\
7 & 0,840 & 0,861 & 0,855 & 0,444 & Valid \\
8 & 0,841 & 0,790 & 0,947 & 0,444 & Valid \\
9 & 0,784 & 0,746 & 0,821 & 0,444 & Valid \\
10 & 0,790 & 0,621 & 0,933 & 0,444 & Valid \\
\hline
\end{tabular}

Sumber : data primer diolah 2020

Tingkat reliabilitas diukur dengan perbandingan antara nilai Cronbach's Alpha > 0,60 (nilai yang sudah ditentukan oleh rumus).

\section{Tabel 3. Hasil Uji Reliabilitas}

\begin{tabular}{lcc}
\hline \multicolumn{1}{c}{ Variabel } & $\begin{array}{c}\text { Cronbach's } \\
\text { Alpha }\end{array}$ & Keterangan \\
\hline Produk $\left(\mathrm{X}_{1}\right)$ & 0,901 & Reliabel \\
Harga $\left(\mathrm{X}_{2}\right)$ & 0,897 & Reliabel \\
Keputusan Pembelian Secara Online $(\mathrm{Y})$ & 0,966 & Reliabel
\end{tabular}

Sumber : data primer diolah 2020

Hasil uji reliabilitas menunjukkan bahwa hasil nilai reliabilitas tersebut keseluruhan nilai Cronbach's alpha > 0,60 yang artinya semua variabel tersebut layak digunakan sebagai alat ukur 
Dalam penyebaran questioner kepada 96 responden pengguna batik pada marketplace duetoko didapat hasil sebagai berikut :

Tabel 4. Jawaban responden mengenai Produk

\begin{tabular}{clc}
\hline nomor & \multicolumn{1}{c}{ Pernyataan } & score \\
\hline 1 & Corak produk batik di duetoko bervariasi & 432 \\
2 & Ukuran produk batik di duetoko bervariasi & 437 \\
3 & Jenis produk batik yang disediakan oleh duetoko sangat beragam & 433 \\
4 & Kualitas produk di duetoko sangat baik & 432 \\
5 & Duetoko selalu mengeluarkan produk yang berkualitas & 431 \\
6 & Desain batik di Duetoko sangat sangat bagus & 427 \\
7 & Bahan yang digunakan untuk produksi batik di duetoko tidak mudah & 421 \\
8 & luntur & 430 \\
9 & zotif batik sangat beragam dan mengikuti trend perkembangan & 407 \\
10 & Merek batik di Duetoko mudah untuk dikenal dan di ingat & 418 \\
\hline
\end{tabular}

Sumber : data primer diolah 2020

Dari hasil jawaban mengenai produk pada kuesioner diatas maka perlu untuk menjadi perhatian pada produsen batik pekalongan untuk lebih menambah variasi ukuran pada batik di duetoko sehingga batik pekalongan tersebut dapat diminati dan digunakan .

Tabel 5. Jawaban responden mengenai harga

\begin{tabular}{clc}
\hline nomor & \multicolumn{1}{c}{ Pernyataan } & score \\
\hline 1 & Harga batik di Duetoko terjangkau oleh semua kalangan & 430 \\
2 & Harga batik di Duetoko bervariasi sesuai bahan & 428 \\
3 & $\begin{array}{l}\text { Harga batik di duetoko lebih murah dibandingkan membeli ditoko } \\
\text { sejenis }\end{array}$ & 419 \\
4 & $\begin{array}{l}\text { Harga batik di Duetoko kualitas produknya sesuai dengan yang } \\
\text { diinginkan }\end{array}$ & 431 \\
5 & Harga produk sesuai dengan variasi barang yang didapat & 426
\end{tabular}


Harga batik yang dikeluarkan Duetoko sesuai dengan model dan ukuran

Harga batik yang dikeluarkan Duetoko sesuai dengan jenis

7 bahannya

Harga batik di Duetoko memiliki manfaat yang ekonomis

8 dibandingkan produk lain

9

Harga yang ditetapkan oleh Duetoko bersaing dengan perusahaan lain

Duetoko memberikan promo gratis ongkir kepada pelanggan yang membeli dalam jumlah banyak

Sumber : data primer diolah 2020

Dari jawaban mengenai harga pada questioner diatas maka dapat disimpulkan bahwa harga batik di Duetoko terjangkau oleh semua kalangan atau konsumen penggunanya, sehingga harga batik di Duetoko harus mampu bersaing dengan perusahaan sejenis lainnya

Tabel 6. Jawaban responden mengenai Keputusan Pembelian

\begin{tabular}{|c|c|c|}
\hline nomor & $\begin{array}{l}\text { Pernyataan } \\
\end{array}$ & score \\
\hline 1 & $\begin{array}{l}\text { Dalam memenuhi kebutuhan saya memantapkan untuk membeli } \\
\text { batik di Duetoko }\end{array}$ & 409 \\
\hline 2 & $\begin{array}{l}\text { Saya memutuskan membeli batik di Duetoko karena sesuai } \\
\text { dengan keinginan dan kebutuhan }\end{array}$ & 420 \\
\hline 3 & $\begin{array}{l}\text { Saya yakin sudah mengambil keputusan yang tepat saat membeli } \\
\text { produk batik di duetoko }\end{array}$ & 417 \\
\hline 4 & Duetoko menjadi tempat bagi saya mencari model batik terbaru & 415 \\
\hline 5 & Saya membeli produk batik duetoko lebih dari satu kali & 394 \\
\hline 6 & $\begin{array}{l}\text { Kepuasan yang saya rasakan akan membuat saya untuk } \\
\text { melakukan pembelian ulang di Duetoko }\end{array}$ & 410 \\
\hline 7 & $\begin{array}{l}\text { Saya melakukan pembelian batik di Duetoko karena berdasarkan } \\
\text { keberagaman desain yang ditawarkan }\end{array}$ & 417 \\
\hline 8 & $\begin{array}{l}\text { Saya akan merekomendasikan kepada pedagang UKM batik } \\
\text { untuk membeli batik di duetoko }\end{array}$ & 419 \\
\hline 9 & $\begin{array}{l}\text { Saya akan merekomendasikan batik kepada teman dan orang- } \\
\text { orang yang membutuhkan batik }\end{array}$ & 417 \\
\hline 10 & $\begin{array}{l}\text { Saya akan merekomendasikan batik di Duetoko melalui media } \\
\text { sosial }\end{array}$ & 412 \\
\hline
\end{tabular}

Sumber : data primer diolah 2020 
Dari jawaban diatas mengenai keputusan pembelian, maka dapat disimpulkan bahwa konsumen pengguna batik di Duetoko memutuskan akan membeli batik di Duetoko karena sesuai dengan kebutuhan dan keinginannya, dan mereka yakin dengan membeli batik di Duetoko merupakan suatu keputusan yang tepat

\section{PEMBAHASAN}

\section{Pengaruh Produk Terhadap Keputusan pembelian secara online}

Hasil jawaban responden dan hasil uji korelasi diketahui bahwa keputusan pembelian secara online dapat dipengaruhi oleh produk memiliki nilai koefisien korelasi (r) yaitu 0,594 artinya bahwa produk $\left(\mathrm{X}_{1}\right)$ memiliki hubungan yang kuat terhadap keputusan pembelian secara online $(\mathrm{Y})$. Nilai koefisien determinasi dengan persentase kontribusi pengaruh variabel produk $\left(\mathbf{X}_{\mathbf{1}}\right)$ terhadap keputusan pembelian secara online (Y) sebesar 35,3\% sedangkan sisanya 64,7\% merupakan kontribusi dari faktor yang tidak diteliti seperti promosi, distribusi, brand image, kemasan dan lain sebagainya.

Hasil uji hipotesis menggunakan uji $\mathrm{t}$ diketahui bahwa dengan melihat perbandingan $t_{\text {tabel }}$ 1,661 dengan $t_{\text {hitung }}$ 7,168 maka $t_{\text {hitung }}>t_{\text {tabel }}$ Sehingga Ho ditolak dan Ha diterima, dapat diartikan bahwa terdapat pengaruh produk terhadap keputusan pembelian secara online, dan produk memberikan pengaruh positif dan signifikan terhadap keputusan pembelian secara online.

Penelitian ini sesuai dengan penelitian yang dilakukan oleh (Aryani , 2016) (Yuniati, 2016) dan (Saputri , 2016), bahwa produk memiliki pengaruh yang signifikan terhadap keputusan pembelian secara online.

Teori yang menyatakan bahwa faktor produk memiliki hubungan yang dapat mempengaruhi pertimbangan bagi konsumen bahwa produk yang dijual harus mempunyai kualitas dan penampilan yang menarik, unik sehingga membuat konsumen untuk membuat keputusan pembelian (Swasta, 2014). Apabila produk dapat memenuhi kebutuhan dan mereka merasa senang memilikinya maka konsumen akan membeli produk secara terus menerus (Kanuk, 2014)

\section{Pengaruh Harga Terhadap Keputusan pembelian secara online}

Hasil Uji hipotesis secara parsial dapat diketahui bahwa harga berpengaruh terhadap keputusan pembelian secara online. Dengan perbandingan $t_{\text {tabel }}$ sebesar 1,661 
dengan $t_{\text {hitung }}$ sebesar 8,628 maka $t_{\text {hitung }}>t_{\text {tabel }}$ sehingga Ho ditolak dan Ha diterima artinya terdapat pengaruh harga terhadap keputusan pembelian.

Koefisien determinasi harga secara signifikan mempengaruhi keputusan pembelian secara online dengan nilai signifikan sebesar 0,000. Maka harga berpengaruh positif dan signifikan terhadap keputusan pembelian secara online.

Penelitian ini sesuai dengan penelitian yang dilakukan oleh (Saputri ,2016). (Devi , 2019), menunjukkan bahwa harga berpengaruh secara parsial terhadap keputusan pembelian.

Dengan penelitian sebelumnya terbukti bahwa dalam penelitian ini sesuai, dimana harga yang murah dan terjangkau dapat membuat konsumen melakukan keputusan pembelian sehingga konsumen lebih hemat melakukan transaksi menggunakan aplikasi online Duetoko.

Pada teori dinyatakan bahwa harga adalah salah satu penentu pembeli menentukan keputusan pembelian. Melalui harga akan membantu pembeli mengalokasikan daya belinya pada jenis barang yang ada. Dari barang yang tersedia pembeli juga akan membandingkannya dari segi harga untuk mengalokasikan dana yang dimiliki, (Tjiptono, 2008)

\section{Pengaruh Produk dan Harga Terhadap Keputusan pembelian secara online}

Dari hasil uji hipotesis secara simultan dapat diketahui bahwa Nilai $F_{\text {hitung }}>F_{\text {tabel }}$ $(31,187>3,15)$. Dengan demikian $\mathrm{H}_{0}$ di tolak dan $\mathrm{H}_{\mathrm{a}}$ diterima. Artinya variabel produk dan harga secara bersama sama berpengaruh terhadap Keputusan Pembelian secara online.

Dari hasil nilai koefisien determinasi berganda $\left(\mathrm{R}^{2}\right)$ menunjukkan bahwa antara variabel Produk $\left(\mathrm{X}_{1}\right)$ dan harga $\left(\mathrm{X}_{2}\right)$ terhadap keputusan pembelian (Y) memiliki kontribusi sebesar 48,2\%, sedangkan sisanya 51,8\% dipengaruhi oleh variabel lain yang tidak di analisis.

Penelitian ini juga sesuai dengan penelitian yang dilakukan oleh (Yuniarti , 2016), (Nurmadina, 2016), ( Devi 2019 ) bahwa faktor produk dan harga berpengaruh secara simultan terhadap keputusan pembelian secara online. 
Teori menyatakan bahwa Produk dan Harga juga merupakan bagian penting dari strategi bauran pemasaran dan memiliki peran sangat penting yang mampu mempengaruhi keputusan pembelian, Kotler (2017)

Dari penelitian sebelumnya dan teori terbukti bahwa penelitian ini sudah sesuai, dimana produk yang baik dan harga yang murah membuat konsumen melakukan keputusan pembelian sehingga konsumen lebih hemat melakukan transaksi menggunakan aplikasi online Duetoko.

\section{KESIMPULAN}

Berdasarkan hasil yang diperoleh, maka dapat simpulan :

1. Berdasarkan hasil analisa data, maka diketahui bahwa produk berpengaruh positif dan signifikan terhadap keputusan pembelian secara online. taraf produk signifikansi sebesar 0,000. Yang menunjukkan bahwa tingkat signifikansi 0,000 $<0,05$.

2. Berdasarkan hasil analisa data diketahui bahwa harga berpengaruh positif dan signifikan terhadap keputusan pembelian secara online pada marketplace Duetoko. Taraf signifikan harga sebesar 0,000. Yang menunjukkan bahwa tingkat signifikansi $0,000<0,05$.

3. Berdasarkan hasil analisa data diketahui bahwa produk dan harga berpengaruh positif dan signifikan terhadap keputusan pembelian secara online pada marketplace Duetoko. Taraf signifikan harga sebesar 0,000. Yang menunjukkan bahwa tingkat signifikansi $0,000<0,05$.

\section{KETERBATASAN PENELITIAN}

Meskipun studi ini penting, studi ini juga memiliki beberapa kekurangan baik sampel untuk sebagai kompetitif belajar yang terbatas. Generalisasi temuan akan lebih baik dengan sampel yang lebih besar ukuran. Selain itu, sampel dapat diperluas ke seluruh Indonesia maupun luar negri dengan waktu yang lebih panjang. Ini akan membantu menawarkan gagasan yang realistis tentang pengaruh produk dan harga pada keputusan pembelian produk batik pekalongan dengan aplikasi Duetoko. Pembatasan tersebut merupakan kesempatan bagi para peneliti selanjutnya untuk memperluas kajiannya ke konteks yang berbeda - beda baik nasional maupun internasional, sehingga seluk-beluk penciptaan produk yang positif dapat ditemukan dengan lebih baik. 


\section{DAFTAR PUSTAKA}

Anang, F. (2019). “Pemasaran Dasar dan Konsep”. CV. Penerbit Qiara Media.

Apriyanto. 2016. Mengapa Situs Marketplace di Indonesia Bisa Menjadi Begitu Populer. From https://id.techinasia.com/talk/populernya-situs-marketplace-di-indonesia

Artaya, P., \& Purworusmiardi, T. (2019). Efektifitas Marketplace Dalam Meningkatkan Konsentrasi. April.

Brunn Peter, Jensen Martin, Skovgaard Jakob. 2002. eMarketplaces: Crafting A Winning Strategy. European Management Journal Vol. 20, No. 3, pp. 286-298

Devi. (2019). Pengaruh Kualitas Produk, Harga dan Promosi Terhadap Keputusan Pembelian pada Marketplace Shopee. (Studi Kasus Pada Mahasiswa di Surabaya), Jurnal Penelitian, Universitas Islam Negeri Sunan Ampel Surabaya.

Fandy, T. (2015). "Strategi Pemasaran" (Distribusi, Pelanggan, Pasar, Branding, Produk dan Harga). CV. ANDI OFFSET, Yogyakarta.

Husnan, d. J. (2015). “Buku Pintar Bisnis Online”. PT. Elex Media Komputindo Kelompok Gramedia, Anggota IKAPI, Jakarta.

Internet, P. P. (t.thn.). Diambil kembali dari https://mentari.net.id/indonesia-gunakaninternet-isp-kuningan.html/APJII.

Laudon, K.C. \& Traver, C. G.(2014). E-Commerce : business, technology, society. 10 Edition. Diakses pada 31 Maret 2017, dari www.academia.edu

Marketplace, P Devi, L. kurnia intan. (2019). Pengaruh kualitas produk, harga dan promosi terhadap keputusan pembelian pada marketplace Shopee. Skripsi.. O. (t.thn.). Diambil kembali dari ttps://rectmedia.com /insight - untuk-tingkatkanpenjualan-online-ramadhan-2018

Meithina, I. (2019). “Pemasaran dan Kepuasan Pelanggan”. Unitomo Press, Surabaya Jawa Timur, Indonesia.

Ningsih, S. K. W. (2016). Rancang Bangun sistem informasi UKM sebagai sarana perdagangan batik dengan e-Marketplace di Pekalongan 8(9), 1149-1151.

Kanuk, S. (2014). Perilaku Konsumen (S. Bambang (ed.); 7th ed.). PT Indeks Group Gramedia.

Rahman, F., Kholid, M., Fakultas, M., \& Administrasi, I. (2017). Strategi UMKM Dalam Membangun Brand Toko Online Di Marketplace (Studi pada komunitas Tokopedia 
KINERJA Jurnal Ekonomi dan Bisnis Vol. 4 No. 1 - Desember 2021

di Kota Bekasi). Jurnal Administrasi Bisnis (JAB)|Vol, 53(1), 39-48.

Sugiono. (2017). Metode Penelitian kuantitatif kualitatif dan $R \& D$ (26th ed.). Alfabeta.

Susanto, A., Sari, C. A., Moses, D. R. I., Rachmawanto, E. H., \& Mulyono, I. U. W. (2020). Implementasi Facebook Marketplace untuk Produk UMKM sebagai Upaya Peningkatan Pemasaran dan Penjualan Online. Abdimasku: Jurnal Pengabdian Masyarakat, 3(1), 42. https://doi.org/10.33633/ja.v3i1.64

Taryadi, Yunianto, E., \& Royani, N. I. (2015). Analisis Tingkat Kesiapan Adopsi EMarketplace Umkm Batik Di Kota Pekalongan. Litbang Kota Pekalongan, 8, 1931.

Wahana, A. (2018). Rancang Bangun Marketplace Produk Kewirausahaan Mahasiswa Upy Berbasis Content Management System. Jurnal Dinamika Informatika, 7(1), 7381. 